\title{
Handbook of Capillary and Microchip Electrophoresis and Associated Microtechniques (3rd Edn.)
}

\author{
(J. P. Landers, ed., CRC Press, Taylor \& Francis Group, Boca Raton, \\ London, New York, 2008, 1567 p., UK Pound Price 109.00)
}

DOI: $10.1134 / \mathrm{S} 0006297908120080$

The book consists of five parts and 55 chapters written by 126 experts from various countries.

Part I includes chapters on the bases and methodology of capillary electrophoresis (CE).

Chapter 1 is an introduction to CE. Here various types of CE, experimental conditions, and data analysis are discussed.

Chapter 2 characterizes methods of protein analysis where $\mathrm{CE}$ is employed.

Chapters 3 and 4 are devoted to micellar electrokinetic chromatography and $\mathrm{CE}$ for pharmaceutical analysis, respectively.

Chapter 5 characterizes principles and practice of capillary electrochromatography.

Chapters 6 and 7 deal with application of CE for analysis of nucleic acids and carbohydrates.

Chapter 8 contains data about using the combination of $\mathrm{CE}$ and mass spectrometry as an effective analytical method for proteomic analysis.

Chapters 9 and 10 contain data about light-based detection methods in CE and microfluid devices for electrophoretic separation.

Part II A is devoted to characterization of various types of CE.
Chapters 11-19 contain data about CE employed for study of DNA sequencing and genotyping, analysis of single cells, computerization of $\mathrm{CE}$, and isoelectric focusing in capillary systems.

Part II B (chapters 20-31) describes capillary based systems focusing on specialized methods and technologies. There are data about CE in subcellular analysis, glycoprotein study, post-translation modification of proteins and peptides, clinical investigations, food analysis, and forensic applications.

In part III A (chapters 32-43), electrophoresis on microchips (EM) is described. Here there are data related to cell manipulation on the micron scale, microchip immunoassays, electrophoretic microdevices for clinical diagnostics, and others approaches.

Part III B (chapters 43-55) includes specialized methods and technologies of EM for cell analysis, DNA structure, and various combinations of EM and mass spectrometry.

Each chapter contains a basic bibliography, and there is a subject index at the end of the book. This book is quite valuable theoretically and methodologically for specialists of various fields of analytical chemistry and biochemistry, molecular biology, biotechnology, and medicine and also for teachers and students of colleges and universities specialized in bioanalysis.

G. Ya. Wiederschain, Doctor of Biological Sciences 